http://dx.doi.org/10.32929/2446-8355.2019v28n1p42-49

\title{
TOXICIDADE DE ALUMÍNIO NA GERMINAÇÃO DE SEMENTES DE Cynara scolymus $\mathbf{L}$.
}

\author{
Raquel Stefanello ${ }^{1 *}$, Patrícia Carine Hüller Goergen ${ }^{2}$
}

\author{
${ }^{1}$ Bióloga, Dr ${ }^{\mathrm{a}}$ em Agronomia, Departamento de Biologia, Universidade Federal de Santa Maria, Santa Maria, \\ RS. *E-mail do autor correspondente: raquelstefanello@yahoo.com.br \\ ${ }^{2}$ Engenheira Agrônoma, Doutoranda do Programa de Pós-graduação em Agronomia, Departamento de \\ Fitotecnia, Universidade Federal de Santa Maria, Santa Maria, RS.
}

Recebido: 08/02/2018; Aceito: 26/03/2019

RESUMO: A contaminação da água e dos solos com elementos tóxicos consiste em um grande problema ambiental com implicações para a saúde humana e animal. Entre os metais tóxicos, o alumínio $(\mathrm{Al})$ representa um entrave para a agricultura, podendo causar diversos danos às plantas diminuindo sua produtividade. Assim, objetivou-se com este trabalho avaliar a tolerância ao Al no processo germinativo das sementes de alcachofra. Para tal, as sementes foram colocadas sobre papel embebido em solução aquosa de cloreto de alumínio nas concentrações correspondentes a zero; 30, 60, 90 e $120 \mathrm{mg} \mathrm{L}^{-1}$. Os parâmetros avaliados foram: percentagem de germinação, primeira contagem, comprimento e massa seca de plântulas. Os resultados obtidos indicam que concentrações de $\mathrm{Al}$ acima de $30 \mathrm{mg} \mathrm{\textrm {L } ^ { - 1 }}$ ocasionam redução do comprimento total das plântulas de alcachofra, não influenciando na percentagem de germinação das sementes. Conclui-se, portanto, que as sementes de alcachofra toleram moderadamente o $\mathrm{Al}$ nos níveis propostos neste trabalho.

Palavras-chave: Alcachofra. Processo germinativo. Cloreto de alumínio.

\section{ALUMINUM TOXICITY ON THE GERMINATION OF Cynara scolymus L. SEEDS}

ABSTRACT: The contamination of water and soil with toxic elements is a major environmental problem having implications for human and animal health. Among the toxic metals, aluminum (Al) represents an obstacle to agriculture, which can cause different damages to the plants, reducing their productivity. The objective of this study was to evaluate Al tolerance of artichoke during the germination process. Seeds were placed on paper embedded in an aqueous solution of aluminum chloride at concentrations of zero, 30, 60, 90 and $120 \mathrm{mg} \mathrm{L}^{-1}$. Parameters evaluated were germination percentage, first count, length and dry mass of seedlings. The results obtained indicate that concentrations of $\mathrm{Al}$ above $30 \mathrm{mg} \mathrm{L}^{-1}$ caused a reduction in the total length of seedlings artichoke; however, Al concentrations were not able to influence seed germination percentage. In conclusion, artichoke seeds can be moderately tolerant to increasing levels of $\mathrm{Al}$.

Key words: Artichoke. Germination process. Aluminum chloride. 


\section{INTRODUÇÃO}

A contaminação da água e dos solos com elementos tóxicos consiste em um grande problema ambiental com implicações para a saúde humana e animal. Dentre os elementos tóxicos no solo destaca-se o alumínio (Al) que, quando em excesso, pode causar diversos danos às plantas diminuindo sua produtividade (FREITAS et al., 2012).

O Al é um elemento abundante nos solos, e seu teor disponível ou livre na forma de $\mathrm{Al}^{3+}$ na solução do solo depende do $\mathrm{pH}$. Em solos com $\mathrm{pH}$ acima de 5,5, geralmente ocorre em baixas concentrações, e está presente em altas concentrações em solos com pH mais baixo. O principal interesse em relação ao Al está na capacidade das plantas de tolerar quantidades tóxicas desse elemento $\left(\mathrm{Al}^{3+}\right)$, bastante variável entre as espécies e os genótipos. Existem relatos de efeitos benéficos de baixas concentrações de $\mathrm{Al}$ (entre 71,4 e $185 \mu \mathrm{mol} \mathrm{L}^{-}$ $\left.{ }^{1}\right)$ no solo ou na solução nutritiva, no crescimento das plantas como milho, beterraba e algumas leguminosas tropicais. Em plantas de chá, uma das mais tolerantes ao Al, tem-se observado estímulo no crescimento pela presença deste metal, entretanto, esse efeito benéfico é difícil de quantificar em função do desconhecimento da atividade iônica do Al. A natureza do efeito benéfico do Al no crescimento das plantas não está clara, mas existem evidências de que é um efeito indireto, na maioria das vezes relacionado com a competição com outros elementos minerais presentes em quantidades tóxicas, principalmente cobre, zinco e fósforo (FURLANI, 2012).

Em solos ácidos, o Al é solubilizado na solução do solo, transformando para sua forma de cátion trivalente $\left(\mathrm{Al}^{+3}\right)$, ficando disponível para a planta e gerando toxidez (KOPITTKE et al., 2015). O estresse por $\mathrm{Al}$ é caracterizado especialmente por causar inibição do crescimento da raiz, como consequência da alteração de diferentes mecanismos e estruturas celulares. Este elemento afeta a síntese de DNA e a regulação de proteínas que controlam o ciclo celular. A toxicidade por $\mathrm{Al}$ causa rompimento da homeostase de espécies reativas de oxigênio/ $\mathrm{Ca}^{2+}$ e a sinalização mediada por $\mathrm{Ca}^{2+}$, considerados eventos chave na indução de danos no DNA ou morte celular em plantas (ACHARY et al., 2013).

A investigação do desenvolvimento das plantas em diferentes níveis de contaminação por Al vem sendo realizada através de estudos como, por exemplo, em Conyza spp. (YAMASHITA; GUIMARÃES, 2011); arroz (FREITAS et al., 2012; ALIA et al., 2015); milho (NASR, 2013; MILANE et al., 2014; MALEKZADEH et al., 2015); pinhão-manso Jatropha curcas (LANA et al., 2013; MACHADO et al., 2015); chia (STEFANELLO et al., 2016). No entanto, não foram encontrados estudos que avaliaram os efeitos tóxicos do Al na germinação de sementes de alcachofra.

A alcachofra (Cynara scolymus L., Asteraceae) é cultivada através de sementes e originária da região mediterrânica da Europa, sendo rica em compostos de polifenóis bioativos, principalmente flavonóides, cinarina, luteolina, ácido clorogênico, além de fibras, vitaminas e minerais dietéticos (NEGRO et al., 2012). Tradicionalmente, as folhas de alcachofra são indicadas para a melhoria da função do aparelho digestivo e urinário (KÜSKÜKIRAZ et al., 2010), para o tratamento e prevenção de doenças hepáticas, distúrbios da 
vesícula biliar e dispepsia (NEGRO et al., 2012; SANNIA, 2010), diabetes, sobrepeso e obesidade (LOI et al., 2013).

Considerando que as altas concentrações de $\mathrm{Al}$ afetam negativamente a germinação de sementes, e acreditando ser benéfico o conhecimento dos efeitos deste metal tóxico sobre a germinação, o crescimento e o desenvolvimento das plantas, a fim de auxiliar na adequada recomendação para o plantio nestas situações, objetivou-se com esse estudo verificar a tolerância ao Al no processo germinativo das sementes de alcachofra.

\section{MATERIAL E MÉTODOS}

O estudo foi desenvolvido no Laboratório de Genética Vegetal, do Departamento de Biologia, Centro de Ciências Naturais e Exatas da Universidade Federal de Santa Maria (RS). As sementes de alcachofra roxa (Cynara scolymus L.) foram adquiridas da empresa Feltrin Sementes - Farroupilha, RS. Para a avaliação do efeito tóxico do alumínio (Al) no processo germinativo, as sementes de alcachofra foram semeadas em substrato papel embebido em solução aquosa de cloreto de alumínio $\left(\mathrm{AlCl}_{3}\right)$, nas concentrações correspondentes a zero (controle); 30, 60, 90 e $120 \mathrm{mg} \mathrm{L}^{-1}$. O nível zero correspondeu à testemunha, onde foi utilizada apenas água destilada.

O efeito tóxico do Al no processo germinativo das sementes foi avaliado através dos seguintes testes (BRASIL, 2009):

Germinação: realizado com quatro repetições de 100 sementes, distribuídas em caixas plásticas (gerbox) sobre três folhas de papel germitest ${ }^{\circledR}$ umedecidas com água destilada ou solução, na proporção de 2,5 vezes o peso do papel. Após a semeadura, as caixas gerbox foram mantidas em B.O.D., na temperatura constante de $20^{\circ} \mathrm{C}$ em presença de $8 \mathrm{~h}$ de luz e 16 $\mathrm{h}$ sem luz, sendo as contagens realizadas aos sete e 21 dias (quando foi finalizado o teste). Foram avaliadas as plântulas normais, sendo os resultados expressos em percentagem.

Primeira contagem: realizada juntamente com o teste de germinação, onde foi determinada a percentagem de plântulas normais no sétimo dia após a instalação do teste.

Comprimento das plântulas: as plântulas normais foram obtidas a partir da semeadura de quatro repetições de 20 sementes umedecidas com água destilada ou solução. Os rolos de papel contendo as sementes permaneceram em câmara de germinação por sete dias à temperatura de $20^{\circ} \mathrm{C}$, quando então foi avaliado, aleatoriamente, o comprimento total de 10 plântulas em cada repetição, com o auxílio de uma régua milimetrada. $\mathrm{O}$ comprimento médio das plântulas foi obtido somando-se as medidas de cada repetição e dividindo-se pelo número de plântulas normais mensuradas, com resultados expressos em centímetros $(\mathrm{cm})$.

Massa seca das plântulas: determinada primeiramente através da obtenção do peso fresco das dez plântulas, previamente medidas nas quatro repetições e mantidas em sacos de papel, em estufa com temperatura de $60{ }^{\circ} \mathrm{C}$ até a obtenção de massa constante $(48 \mathrm{~h})$. Posteriormente, as plântulas foram novamente pesadas em balança analítica com precisão de $0,001 \mathrm{~g}$, sendo os resultados expressos em miligramas $(\mathrm{mg})$. 
O delineamento experimental utilizado foi o inteiramente casualizado, onde os tratamentos foram constituídos pelas diferentes concentrações das soluções. Os dados foram submetidos à análise de variância pelo teste $\mathrm{F}$ e, quando constatado efeito significativo foi efetuada a análise de regressão pelo programa Sisvar (FERREIRA, 2011).

\section{RESULTADOS E DISCUSSÃO}

A análise de variância indicou diferenças significativas em função dos tratamentos apenas para a variável comprimento total de plântulas (Tabela 1).

Tabela 1. Resumo da análise de variância para as variáveis germinação $(G)$, primeira contagem (PC), comprimento total (CT) e massa seca (MS) de plântulas de alcachofra submetidas a diferentes concentrações de alumínio. Summary of the analysis of variance for the variables germination $(G)$, first count $(F C)$, total length (TL), and dry mass (DM) of artichoke seedlings exposed to different concentrations of aluminum.

\begin{tabular}{lccccc}
\hline Fonte de & Graus de & \multicolumn{4}{c}{ Quadrado médio } \\
\cline { 3 - 6 } variação & liberdade & $\mathrm{G}$ & $\mathrm{PC}$ & $\mathrm{CT}$ & $\mathrm{MS}$ \\
\hline Tratamento & 4 & $71,300^{\text {ns }}$ & $63,700^{\text {ns }}$ & $3,749^{*}$ & $0,0003^{\text {ns }}$ \\
Resíduo & 15 & 48,933 & 43,333 & 0,283 & 0,00002 \\
CV $(\%)$ & & 10,47 & 10,38 & 7,33 & 6,06 \\
\hline
\end{tabular}

${ }^{\text {ns Não significativo. } * \text { Significativo a } 5 \% \text { de probabilidade pelo teste F. CV = coeficiente de variação. }{ }^{n s} \text { Not }}$ significant. * Significant at $5 \%$ probability by the $\mathrm{F}$ test. $C V=$ coefficient of variation.

$\mathrm{Na}$ ausência do $\mathrm{Al}$, as sementes apresentaram em média $74 \%$ e $70 \%$ de plântulas normais no teste de germinação e primeira contagem, respectivamente (Figuras 1A e 1B), não sendo observada redução significativa na percentagem de plântulas normais na maior concentração utilizada (120 mg L $\left.\mathrm{L}^{-1}\right)$. Desta forma, é possível afirmar que concentrações de $\mathrm{Al}$ até $120 \mathrm{mg} \mathrm{L}^{-1}$ não afetam a germinação e o vigor das sementes de alcachofra.

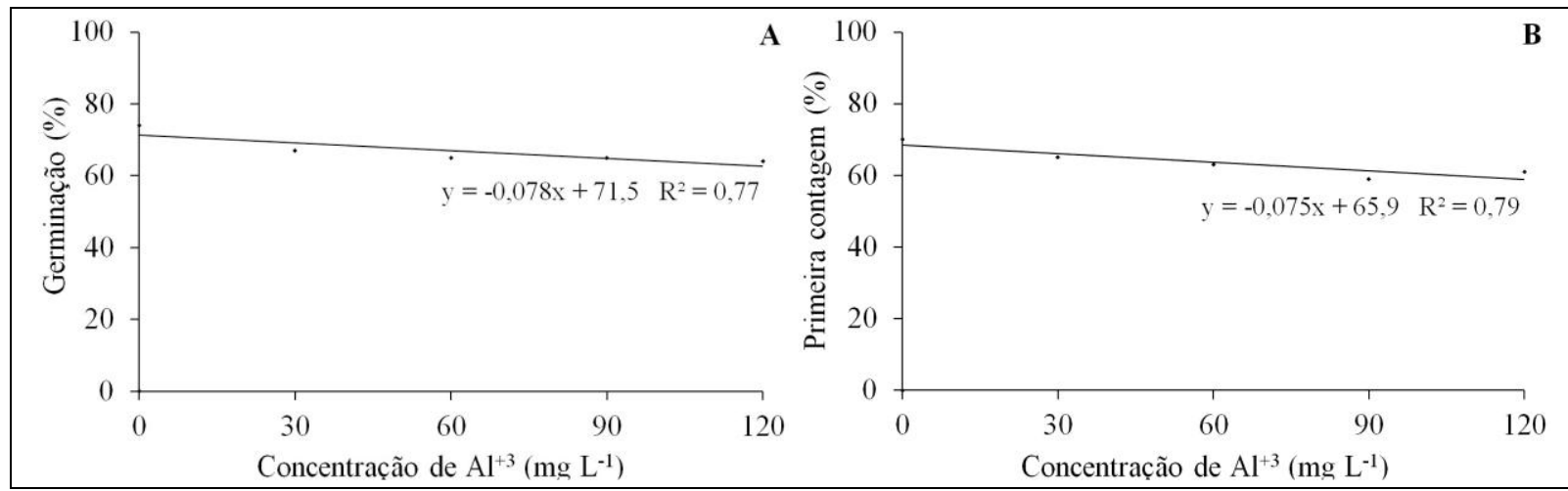

Figura 1. Percentagem de germinação (A) e primeira contagem de germinação (B) de sementes de alcachofra submetidas a diferentes concentrações de alumínio. Percentage of germination (A) and first germination count $(B)$ of artichoke seeds exposed to different concentrations of aluminum.

Resultados semelhantes foram obtidos por Milane et al. (2014) em sementes de milho utilizando de 15 a $75 \mathrm{mg} \mathrm{L}^{-1}$ de $\mathrm{Al}$. Os autores não verificaram alterações na percentagem de germinação e no desenvolvimento inicial das plântulas até $75 \mathrm{mg} \mathrm{L}^{-1}$. No entanto, Yamashita 
e Guimarães (2011) estudando o efeito tóxico de Al em sementes de Conyza spp. verificaram que a germinação foi influenciada negativamente pela presença de $\mathrm{Al}$, sendo a percentagem de plântulas normais reduzida significativamente a partir de $135 \mathrm{mg} \mathrm{L}^{-1}$. Da mesma forma, Nasr (2013) observou que o Al nas concentrações de 50 a $200 \mathrm{mg} \mathrm{L}^{-1}$ afetou a germinação, o comprimento da parte aérea e da raiz e a biomassa seca do milho em relação ao controle. De acordo com Rampim e Lana (2013), a tolerância ao Al é controlada geneticamente e as espécies diferem consideravelmente quanto ao grau dessa tolerância.

O Al quando em excesso é muito tóxico para a germinação das sementes em plantas tolerantes e suscetíveis (NASR, 2013). De todos os sintomas fitotóxicos induzidos por Al, a perturbação da divisão celular e do crescimento do ápice da raiz tem o impacto mais significativo no rendimento das plantas (LIANG et al., 2013). Assim, muitos estudos relacionados à redução da fitotoxicidade do Al estão focados nas atividades fisiológicas e moleculares na região da ponta da raiz. A tolerância a este metal tóxico é conseguida através da secreção de ácidos orgânicos para ligar $\mathrm{Al}^{3+}$ à ponta das raízes (YANG et al., 2013) e à resistência interna, por modificação de processos celulares através da desintoxicação apoplástica e simplástica do Al incorporado (HUANG et al., 2012).

Em relação ao comprimento (Figura 2A), foram observadas diferenças significativas dos tratamentos sobre o comprimento total das plântulas de alcachofra com valores variando de $8,65 \mathrm{~cm}$ (controle) a $6,05 \mathrm{~cm}\left(120 \mathrm{mg} \mathrm{L}^{-1}\right)$. Além disso, não houve diferença na massa seca das plântulas (Figura 2B).

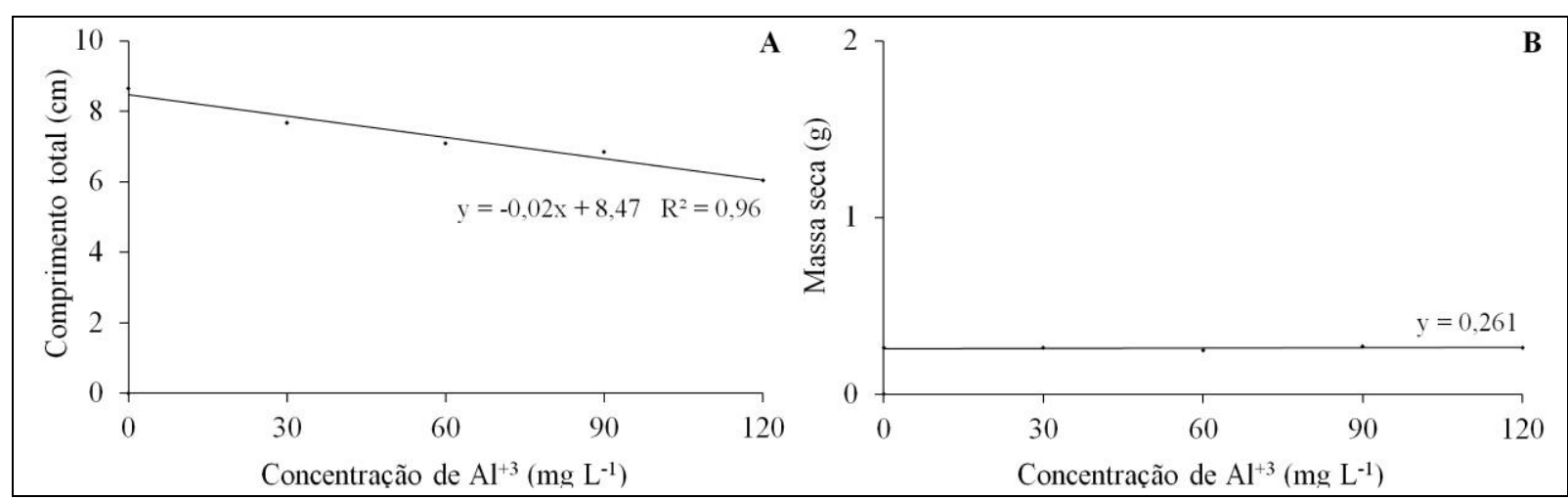

Figura 2. Comprimento (A) e massa seca (B) de plântulas de alcachofra submetidas a diferentes concentrações de alumínio. Length (A) and dry mass (B) of artichoke seedlings exposed to different concentrations of aluminum.

Os resultados deste trabalho corroboram com Machado et al. (2015), que verificaram reduções significativas no comprimento total das plântulas de pinhão-manso (Jatropha curcas) à medida que se aumentavam as concentrações de $\mathrm{Al}$ tóxico (até $80 \mathrm{mg} \mathrm{L}^{-1}$ ). Também, Lana et al. (2013), utilizando concentrações de 200 a $1000 \mu \mathrm{mol} \mathrm{L}^{-1}$ de $\mathrm{Al}$, observaram os sintomas de toxicidade bastante evidentes, manifestando-se através de espessamento e amarelecimento de pontas das raízes de pinhão-manso. No entanto, a quantidade de Al usada não afetou o volume e a matéria seca das raízes. Da mesma forma, Alia et al. (2015) concluíram que em elevadas concentrações de Al (até $100 \mu \mathrm{M}$ ) as estruturas celulares das raízes do arroz foram altamente danificadas e, Malekzadeh et al. (2015) analisando o efeito da toxicidade do $\mathrm{Al}$ em milho, observaram redução do comprimento da parte aérea e da raiz das 
plântulas quando expostas a altas concentrações $(100 \mu \mathrm{M}$ de $\mathrm{Al})$. Por outro lado, embora Stefanello et al. (2016) não tenham verificado diferenças significativas no comprimento total, da parte aérea e da raiz de chia (Salvia hispanica), observaram sintomas típicos de toxidez como raízes mais finas com escurecimento dos ápices, nas concentrações de 30 a $120 \mathrm{mg} \mathrm{L}^{-1}$ de Al.

Diversos estudos demonstram que mesmo em baixas concentrações, o Al solúvel é tóxico para a maioria das plantas. Esse elemento é absorvido pelas raízes, causando fitotoxicidade, primeiramente por influenciar o crescimento das células na zona de alongamento da raiz, impedindo os mecanismos de absorção e transporte de água e dos nutrientes (BIAN et al., 2013). De acordo com Gupta et al. (2013), o efeito tóxico do Al ocasiona mudanças na morfologia da raiz, sendo observada inibição da elongação radicular, resultando em raízes curtas com ápices mais grossos, e com poucos ou nenhum pelo radicular, além de diminuição do número de raízes laterais (MACEDO et al., 2011).

\section{CONCLUSÃO}

As concentrações de $\mathrm{Al}$ acima de $30 \mathrm{mg} \mathrm{L}^{-1}$ ocasionam redução do comprimento total das plântulas de alcachofra, não influenciando na percentagem de germinação das sementes.

As sementes de alcachofra toleram moderadamente o Al nos níveis propostos neste trabalho.

\section{REFERÊNCIAS BIBLIOGRÁFICAS}

ACHARY, V.; PARINANDI, N.; PANDA, B. Calcium channel blockers protect against aluminium-induced DNA damage and block adaptive response to genotoxic stress in plant cells. Mutation Research, Amsterdam, v. 751, n. 2, p.130-138, 2013.

ALIA, F. J.; SHAMSHUDDIN, J.; FAUZIAH, C. I.; HUSNI, M. H. A.; PANHWAR, Q. A. Effects of aluminum, iron and/or low $\mathrm{pH}$ on rice seedlings grown in solution culture. International Journal of Agriculture and Biology, Pakistan, v. 17, n. 4, p.702-710, 2015.

AMADO, S.; CHAVES FILHO, J. T. Fitorremediação de solos contaminados por metais pesados. Natureza on line, Santa Teresa, v. 13, n. 4, p.158-164, 2015.

BIAN, M.; ZHOU, M.; SUN, D.; LI, C. Molecular approaches unravel the mechanism of acid soil tolerance in plants. The Crop Journal, Amsterdam, v. 1, n. 2, p.91-104, 2013.

BRASIL. Ministério da Agricultura, Pecuária e Abastecimento. Regras para análise de sementes. Brasília, DF: Mapa, 2009. 399 p.

FERREIRA, D. F. Sisvar: a computer statistical analysis system. Ciência e Agrotecnologia, Lavras, v. 35, n. 6, p.1039-1042, 2011.

FREITAS, L. B.; FERNADES, D. M.; MAIA, C. M. Interação silício e alumínio em plantas de arroz de terras altas cultivada sem solo alumínico. Revista Brasileira de Ciência do Solo, Viçosa, v. 36, n. 2, p.507-515, 2012. 
FURLANI, A. M. C. Nutrição mineral. In: KERBAUY, G.B. Fisiologia vegetal. 2 ed. Rio de Janeiro: Guanabara Koogan, 2012. 431 p.

GUPTA, N.; GAURAV, S. S.; KUMAR, A. Molecular basis of aluminum toxicity in plants: A Review. American Journal of Plant Sciences, California, v. 4, n. 12C, p.21-37, 2013.

HUANG, C. F.; YAMAJI, N.; CHEN, Z.; MA, J. F. A tonoplast-localized half-size ABC transporter is required for internal detoxification of aluminum in rice. The Plant Journal, Oxford, v. 69, n. 5, p.857-867, 2012.

KOPITTKE, P. M.; MOORE, K. L.; LOMBI, E.; GIANONCELLI, A.; FERGUSON, B. J.; BLAMEY, F. P. C.; MENZIES, N. W.; NICHOLSON, T. M.; MCKENNA, B. A.; WANG, P.; GRESSHOFF, P. M.; KOUROUSIAS, G.; WEBB, R. I.; GREEN, K.; TOLLENAERE, A. Identification of the primary lesion of toxic aluminum in plant roots. Plant Physiology, Lancaster, v. 167, n. 4, p.1402-1411, 2015.

KÜSKÜ-KIRAZ, Z.; MEHMETÇIK, G.; DOGRU-ABBASOGLU, S.; UYSAL, M. Artichoke leaf extract reduces oxidative stress and lipoprotein dyshomeostasis in rats fed on high cholesterol diet. Phytotherapy Research, London, v. 24, n. 4, p.565-570, 2010.

LANA, M. C.; STEINER, F.; ZOZ, T.; FEY, R.; FRANDOLOSO, J. F. Tolerance of physic nut plants to aluminum activity in nutrient solution. Bioscience Journal, Uberlândia, v. 29, n. 3, p.582-589, 2013.

LIANG, C.; PIÑEROS, M. A.; TIAN, J.; YAO, Z. F.; SUN, L. L.; LIU, J. P.; SHAFF, J.; COLUCCIO, A.; KOCHIAN, L. V.; LIAO, H. Low $\mathrm{pH}$, aluminum, and phosphorus coordinately regulate malate exudation through Gm MT1 to improve soybean adaptation to acid soils. Plant Physiology, Lancaster, v. 161, n. 2, p.1347-1361, 2013.

LOI, B.; FANTINI, N.; COLOMBO, G, GESSA, G.L.; RIVA, A.; CARAI, M. A. Reducing effect of a combination on of Phaseolus vulgaris and Cynara scolymus extracts on food intake and glycemia in rats. Phytotherapy Research, London, v. 27, n. 2, p.258-63, 2013.

MACEDO, F.L.; PEDRA, W.N.; SILVA, S.A.; BARRETO, M.C.V.; SILVA-MANN, R. Efeito do alumínio em plantas de pinhão-manso (Jatropha curcas L.), cultivadas em solução nutritiva. Semina: Ciências Agrárias, Londrina, v. 32, n. 1, p. 157-164, 2011.

MACHADO, J. S.; STEINER, F.; ZOZ, F.; HONDA, G. B.; OLIVEIRA, B. L. N. Effects of aluminum on seed germination and initial growth of physic nut seedlings. Revista de Agricultura Neotropical, Cassilândia, v. 2, n. 1, p.24-31, 2015.

MALEKZADEH, P., MEHR, R. S.; HATAMNIA, A. A. Effects of aluminum toxicity on maize (Zea mays L.) seedlings. Iranian Journal of Plant Physiology, Iran, v. 5, n. 2, p.12891296, 2015.

MILANE, L. V.; RODRIGUES, L. A.; SILVA, J. B.; SILVA, T. R. B.; ALVES, C. Z. Acidez e alumínio na germinação e desenvolvimento inicial de plântulas de milho. Journal of Agronomic Sciences, Umuarama, v. 3, n. 1, p.188-198, 2014. 
NASR, N. Germination and seedling growth of maize (Zea mays L.) seeds in toxicity of aluminum and nickel. Merit Research Journal of Environmental Science and Toxicology, v. 1, n. 5, p.110-113, 2013.

NEGRO, D.; MONTESANO, V.; GRIECO, S.; CRUPI, P.; SARL, I. G.; DE LISI, A; SONNANTE, G. Polyphenol compounds in Artichoke plant tissues and varieties. Journal of Food Science, Raleigh, v. 77, n.2, p.244-252, 2012.

RAMPIM, L.; LANA, M. C. Mecanismo de tolerância interna das plantas ao alumínio. Colloquium Agrariae, Presidente Prudente, v. 9, n. 2, p.72-89, 2013.

SANNIA, A. Phytotherapy with a mixture of dry extracts with hepatoprotective effects containing Artichoke leaves in the management of functional dyspepsia symptoms. Minerva Gastroenterol Dietol, Torino, v. 56, n. 2, p.93-99, 2010.

STEFANELLO, R.; VIANA, B. B.; TABALDI, L.A.; NEVES, L. A. S.; NUNES, U. R. Tolerance of chia (Salvia hispanica) to aluminum. International Journal of Current Research, Índia, v. 8, n. 11, p.42032-42035, 2016.

YAMASHITA, O. M.; GUIMARÃES, S. C. Germinação de sementes de Conyza canadensis e C. bonariensis em função da presença de alumínio no substrato. Ciência Rural, Santa Maria, v. 41, n. 4, p.599-601, 2011.

YANG, L. T.; QI, Y. P.; JIANG, H. X.; CHEN, L. S. Roles of organic acid anion secretion in aluminum tolerance of higher plants. BioMed Research International, New York, v. 2013, p.1-16, 2013. 